\title{
A new standard for flood resistance and resilience of buildings: new build and retrofit
}

\author{
Andrew Tagg ${ }^{1, a}$, Kevin Laverty ${ }^{2}$, Manuela Escarameia ${ }^{1}$, Stephen Garvin ${ }^{3}$, Alan Cripps ${ }^{4}$, Robbie Craig ${ }^{5}$ and Adam \\ Clutterbuck \\ ${ }^{1} \mathrm{HR}$ Wallingford, Howbery Park, Wallingford, Oxfordshire, OX10 8BA, UK \\ ${ }^{2} B S I, 389$ Chiswick High Road, London, W4 4AL, UK \\ ${ }^{3} B R E$, Orion House, SETP, East Kilbride, G75 ORD, UK \\ ${ }^{4}$ RICS, Parliament Square, London SW1P 3AD, UK \\ ${ }^{5}$ Defra, Area 3C, Nobel house, 17 Smith Square, London, SW1P 3JR, UK \\ ${ }^{6}$ Independent
}

\begin{abstract}
With around three million properties in England affected by severe weather-driven surface water (pluvial) flooding, and the number likely to increase as a result of climate change, it is important that homeowners and businesses are encouraged to take steps to minimise the effects of future flood events. This is where property-level protection and building resilience measures are important. However, stakeholders will continue to need assistance and advice on how to select appropriate measures. Based on laboratory testing and other desk studies, a guidance document was developed in 2007 giving advice on resilient approaches for new buildings. This was adopted by many organisations, to inform measures that could be used, particularly to deal with residual flood risks, which cannot always be designed out. Since 2009, through the 'Statement of Principles' with the insurance industry and the NPPF, unsuitable development has been discouraged in areas at high flood risk. However, with the increased awareness of the need to deal with surface water for existing housing stock, a new standard was needed. Therefore the British Standards Institution has developed a new standard (BS 85500) that updates and extends the guidance document, including retrofitting flood resistance and resilience measures to existing properties. This paper outlines the Standard's contents and some of the key issues associated with its development.
\end{abstract}

\section{Need for protection of buildings}

Many international research programmes have shown that rising global temperatures are leading to changes in the mean weather conditions, which across Europe are being seen as warmer and wetter winters, and drier summers. The increased occurrence of extreme weather has also been observed, with more prevalent storm tracks moving across the UK, associated with high winds and heavy rainfall. Experience has shown that all areas of the UK are susceptible, with the storms of winter 2013/2014 being particularly concentrated in the south, and those of winter 2015/2016 in the north.

Following the widespread flooding of summer 2007 and early 2014, flood resistance and resilience have risen higher up the agenda. As a result of the summer 2007 flooding, Sir Michael Pitt [1] made 92 recommendations, of which the following three are relevant to this paper:

- \#11 Building Regulations should be revised to ensure that all new or refurbished buildings in high flood-risk areas are flood resistant or resilient;

- \#12 All local authorities should extend eligibility for home improvement grants and loans to include flood resistance and

a Corresponding author: a.tagg@hrwallingford.com resilience products for properties in high flood-risk areas;

- \#13 Local authorities...should encourage the take-up of property flood resistance and resilience by businesses.

As a result of the extreme winter 2015/16 floods in Cumbria, Lancashire and Yorkshire, the Government has announced a 'resilience review'. While Government policies in the UK do not advocate the building of dwellings in areas with a significant risk of flooding, the current lack of affordable housing in the UK could lead to an increased likelihood of development on low or residual flood risk areas. There are also a significant number of existing properties at risk from surface water flooding that would particularly benefit from resistance and resilience measures. This paper discusses the options for improved protection of buildings and the recent production of new guidance. It is not intended to include here an extensive literature review of the many initiatives undertaken in this field in the UK, rest of Europe or worldwide. Some recent publications provide a good overview of this topic $[2,3]$. 


\section{Resistance and resilience in context}

For the past couple of decades the approach to dealing with floods across Europe has been one of flood risk management, rather than traditional flood prevention using hard flood defences. This is in recognition that flooding can come from many different sources and all should be evaluated and assessed as part of deriving appropriate mitigation measures. Moreover, this accepts that a range of options may be needed to reduce the flood risk to people and properties. Whilst traditional flood defences may provide protection against river and coastal flooding for large communities there will always be some properties that cannot benefit from such schemes. For example, such defences are unlikely to deal adequately with localised pluvial or groundwater flooding. In these cases, homeowners need to have a range of protection or resilience measures they can incorporate into their properties.

In terms of protection of properties, a hierarchy of options has been recognised (Figure 1) which is associated with decreasing residual risk of flooding as each type of option is introduced, although this does depend on the type of flood and building under consideration. At the highest level, avoidance is a preferred option, which comprises a range of measures including location of buildings in areas of least risk (land use planning), or raising properties above the flood level, or use of bunds or other hard defences to keep floodwater away. Resistance includes measures taken at the building level to prevent floodwater entering the building and damaging its fabric. This would include both flood protection products (barriers and flood doors that cover apertures) and resistant materials such as engineering bricks or waterproof renders on the outside.

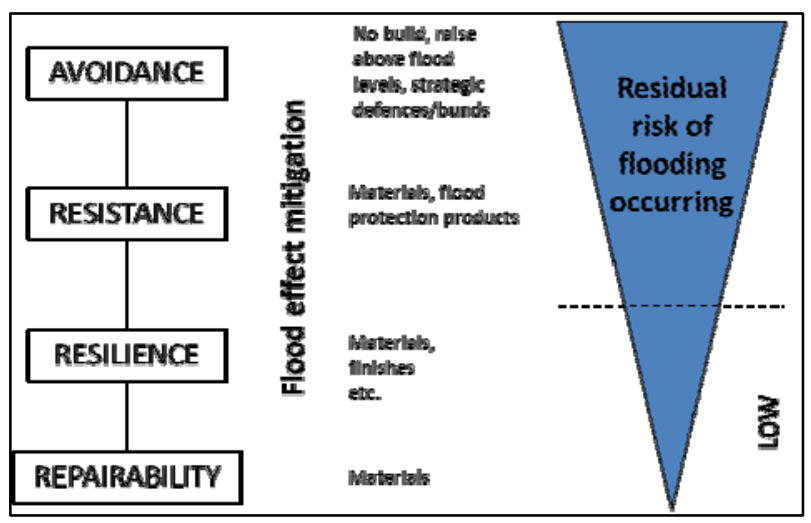

Figure 1. Hierarchy of building protection measures.

Resilience comprises sustainable measures that can be incorporated into the building fabric, fixtures and fittings to reduce the impact of floodwater. Such measures would allow for easier drying and cleaning, ensure that the structural integrity of the building is not compromised and reduce the time required until the building can be re-occupied. Reparability forms a subset of resilience, covering design of elements that facilitate replacement and repair, such as sacrificial finishes.

Resistant and resilient measures can also be viewed according to the risk reduction chain, namely "Assess Avoid - Substitute - Control - Mitigate". This also views avoidance as a primary, high-level option with building measures coming lower down the hierarchy. This would also be where flood insurance has a role, to deal with residual risks that are impractical or costly to design out.

In the UK there has been significant interest in the use of flood resistance products, both at the building scale, to block apertures, but also temporary or demountable barriers that can surround critical infrastructure installations or run along a river bank, as at Shrewsbury and Bewdley in the Severn valley. Testing and certification of these devices is set out in a formal specification PAS1188 [4] which is now in its $3^{\text {rd }} 2014$ iteration. The EU project SMARTeST [5] looked at test specifications in use in the USA and across Europe. Although there has been a significant take-up of such devices, in response to the many flood events over the past two decades, increased use is required if the protection of buildings is to keep pace with the effects of climate change.

\section{Development of the evidence base for resilience}

Starting in about 2003, there have been several initiatives to encourage the use of flood resilient approaches to reduce the adverse impacts of floods, particularly health risks and costs. This included advice from the European Commission, UK Government [6] and the insurance industry [7]. Much of the guidance was concerned with retrofit of existing properties, with little on design standards for new build. Whilst much of the guidance was common across most publications and based on expert opinion, there was limited published technical work on the physical evidence for such advice. Therefore, a project was commissioned in 2005 by DCLG and the Environment Agency (supported by Defra) [8] to undertake new laboratory testing, stakeholder and literature reviews to build such an evidence base that could then inform the development of new guidance.

A literature review found general agreement on the factors and techniques that are important for resistant and resilient building design, although much was based on extrapolations of known behaviour. There was little published scientific research into the performance of construction materials under flood conditions. Additional experiential evidence was collated from personal interviews with those who had first-hand knowledge of drying flooded properties or use of certain methods in the construction industry. Finally, this was complemented by an extensive programme of laboratory tests which for the first time produced quantitative baseline information on the behaviour of materials and elements (walls and floors) under flood conditions (effectively static water pressure). Figure 2 shows one of the test facilities with a typical wall construction subjected to a metre depth of floodwater. 


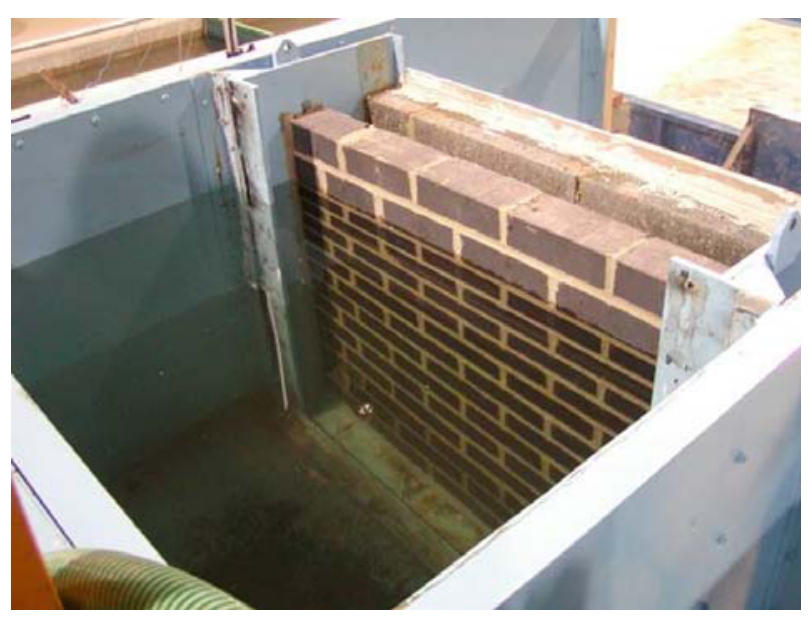

Figure 2. Testing a cavity masonry wall.

On the basis of this new evidence, plus the views of a steering group of industry stakeholders, new government guidance was produced in May 2007 [9] covering flood resilient construction methods for new buildings (see Figure 3). The guidance used a design strategy based on flood depth, such that for smaller floods with shallow depths of water, it was more cost-effective to try and keep water out of the building using resistant materials. For deeper floodwater structural damage could be an issue, as could seepage through the walls and floors. In these cases it was recommended that a water-entry strategy was preferred, with a range of internal measures that could more easily be dried, cleaned, rehabilitated or replaced. The guidance covered discussion of avoidance and resistance measures, plus design and construction options for materials, walls, floors, doors and windows, fittings and services. As this was the only guide available in the UK it was used by certain local authorities when specifying planning conditions for new developments, or when flooded properties were being refurbished.

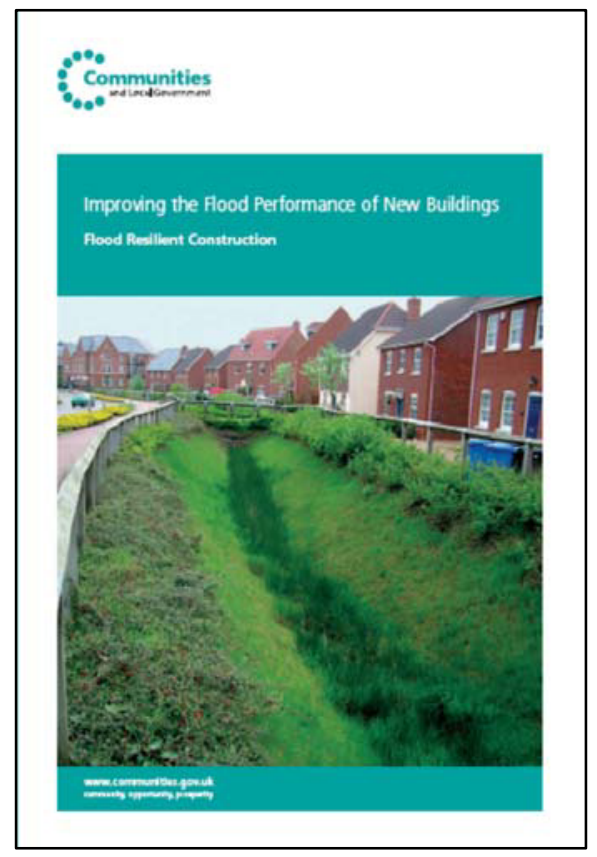

Figure 3. DCLG 2007 guidance

\section{The new British Standard BS 85500}

\subsection{Background}

The British Standards Institution (BSI) is a business services provider whose principal activity is the production of standards and the supply of standardsrelated services. It has strong links to the European (CEN) and international (ISO) standardisation bodies. In 2006, BSI set out its "Rethinking standards in construction" initiative [10], supported under the auspices of the former Department of Trade and Industry. Essentially this was to identify market needs for new standards in the construction and built environment sector. Then in 2010, senior civil servants began reporting to BSI technical committees that, as part of an emerging decentralisation policy, Ministers in the new Coalition Government were proposing to reduce the number of detailed government guidance documents, as this was not seen as the best vehicle for such publications. This presented a major opportunity under the BSI initiative, and accordingly a dedicated committee was set up to oversee this activity.

The document described in the rest of this paper was actually the 'trailblazer' British Standard under this initiative, based on two interlinked guidance documents developed for DCLG: the first was the 2007 one on resilient construction described above; the second an unpublished document dealing with modern methods of construction in flood risk areas. Having made a business case for this new standard and obtained government approval, a technical committee was set up, essentially comprising the authors of this paper, to merge and bring up-to-date the content of the existing guidance. One feature of this agreement between BSI and the government is that in addition to the full standard that BSI sells, there is an associated slimmed-down Core Document that provides a summary of the content, and which is freely available from the BSI web site.

\subsection{Summary of Standard content}

The document [11] starts with the statement of its scope, covering both recommendations of when to adopt resistant or resilient measures, and the provision of guidance on the design and specification for new buildings, extensions and retrofits. There are specific areas that are not covered, such as structural design or design of watertight concrete, and a list of other documents are provided that cover these topics.

The standard's context is built around the undertaking of a flood risk assessment (FRA), which will identify the flood characteristics at the affected site, and by linking these to the proposed design strategies (described below) informs the options for design. The FRA should identify the types of flood hazard at the site, including their depth, duration and frequency. These are the key parameters that should influence the choice of mitigation measures. For example, flooding that persists for many days or weeks is likely to seep through the floor or brickwork of the building in time, and therefore adopting only resistant measures is likely to be futile in the long run. This would apply for significant river flooding or groundwater 
flooding (see Figure 4). However for short duration flash floods that do not reach a significant depth (say below $0.6 \mathrm{~m})$, then attempts to keep water out of the building are to be preferred. For deep flooding there may be structural issues and a qualified engineer should be consulted.

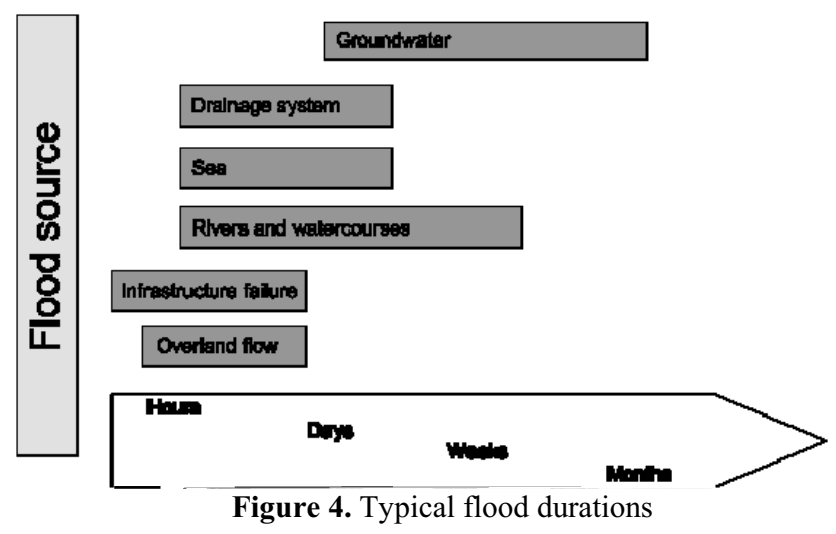

The Standard then looks at the general response of buildings to floodwater, and the various construction elements that will be affected for different depths of water. This includes both physical damage, such as build-up of water and sediment in cavities, but also quality impacts such as mobilisation of ground salts and the growth of fungi and mould in the damp conditions which can damage certain materials. The potential routes of water entry into the building are presented. Here the route through the external fabric of the building and upward movement through the floor are key routes, that may be difficult to deal with for deep or long-duration floodwater. The building construction is broken down into several elements (foundations, basements, floors, walls, door and windows, and fixtures/fittings/services). For each of these, the guidance sets out the particular hazard that affects each element, and the resulting impact. So for example, uplift pressure of water below the building could lead to cracking and heave of solid concrete floors or to structural damage to suspended timber floor joists. Conversely, external cladding and insulation could be affected by high-velocity, debrisladen floodwater, leading to structural damage or silt ingress into the cavity, resulting in a reduction in insulation effectiveness.

Before presenting the main design specifications for each building element, the standard sets out the basis of the proposed design standards. As mentioned above, these depend on the frequency and characteristics of the design flood event, and require consideration of the depth, source, duration and rate of rise of the floodwater. This leads to a hierarchy of strategies, namely avoidance, site layout, water exclusion (resistance) and water entry (resilience). This has been described above in Section 2. Flood depth was assumed to be a key determinant for the use of resistance or resilience measures, mainly due to concerns over the structural stability of buildings if one attempts to keep out deep water. Table 1 summarises this in simple terms.
Table 1 Summary of design strategies

\begin{tabular}{|c|c|}
\hline $\begin{array}{l}\text { Design floodwater depth } \\
\text { above ground floor level }\end{array}$ & Measure \\
\hline Less than $300 \mathrm{~mm}$ & Resistance $^{\mathrm{A})}$ \\
\hline 300 to $600 \mathrm{~mm}$ & Resistance + resilience \\
\hline More than $600 \mathrm{~mm}$ & $\begin{array}{l}\text { Resilience }+ \text { resistance for } \\
\text { lesser events }\end{array}$ \\
\hline
\end{tabular}

Section 7 onwards of the document presents the main recommendations, starting with new buildings and moving onto extensions and retrofits. Key issues for ground floors in new buildings are the potential for uplift pressures or exposure to standing water. For water exclusion, a concrete floor slab of $150 \mathrm{~mm}$ minimum thickness is recommended, based on laboratory testing, to withstand such pressures. Although suspended floors are generally not recommended in flood-prone areas, access to the sub-flood space should be considered to allow for cleaning and drying. The position of damp-proof membranes is important, particularly in relation to insulation materials, with a preference for placing below the slab and correctly bonded to retain a waterproof layer. For a water-entry strategy, key considerations are the floor finishes and insulation. A closed-cell type of insulation is preferred as this will resist deformation and will retain its properties. Two approaches are possible for floor finishes: either use of sacrificial materials that are easily replaced, or ones that withstand exposure to water, such as ceramic or concrete-based tiles, stone or sand/cement screeds. Use of a floor pump is recommended in a low point of the building, so that excess floodwater can be easily removed, which assists in the drying process.

For walls, the Standard recommends keeping water out of the building for shallower flooding (up to $300 \mathrm{~mm}$ or up to $600 \mathrm{~mm}$ if allowed by a structural assessment) using low permeability or low water-absorbing brick- and blockwork and external coatings/render. Solid walls with external insulation are preferred to using cavity construction, but in the latter case closed-cell insulation should be used as this retains its integrity and resists moisture take-up. Schematic examples are provided for different wall constructions, showing suitable internal and external finishes.

For more frequent or higher flood depths, a water entry strategy is recommended in which materials should be used that can be dried quickly or are assumed to be sacrificial. For example, concrete blocks were found to dry quickly even though they had a higher permeability compared to other types of block. Again, closed-cell insulation for the cavity is preferred, as mineral wool batts or blown-in material were found to remain wet for many weeks/months if not dried artificially and also slumped in the cavity. For internal linings, cement renders should be avoided as this can hinder effective drying. Standard gypsum plasterboard is not resilient to floodwater, but this can be used up to the predicted flood level as a sacrificial material, as this can be easily removed and the rest of the wall dried. Anecdotal 
evidence suggests that lime plaster is a good solution, but this needs sufficient time to set and harden before it is fully effective.

In Section 8 the Standard moves onto 'retrofit' of existing properties. For these cases, much of the previous guidance still applies, whether a water exclusion or entry strategy is being considered. In most cases, retrofit will be instigated as a result of a flood event and there will therefore be first-hand knowledge of the form of hazard and the potential impacts. A survey from a qualified expert will ensure that the correct options are considered: these will include water exclusion for the lower depths, water entry above this, and potentially the use of additional flood protection products (barriers, airbrick covers or doors) to provide watertight seals for all major apertures. Some of the key issues to consider as part of the retrofit are:

- Checking the integrity of the damp-proof membranes, and ensuring that any floor insulation and underfloor heating sits above this to prevent water contact;

- Choosing appropriate resilient measures for internal walls, so that this improves drying and cleaning;

- Possibility of water entry through party walls from neighbouring properties;

- Choice of insulation material and future access for drying or replacement after flooding;

- Use of perimeter drains, and sumps and pumps to remove water during future events.

The Standard concludes with guidance on doors, windows and air vents, which considers the risk from floating debris and the need to ensure that these elements can withstand such impacts. Separate guidance is available on the leakage testing of doors [4] so that homeowners can purchase items that have achieved low leakage. Final guidance on fixtures, fittings and services considers the installation of electrical services and heating systems above predicted or observed flood levels to prevent unnecessary damage. Any external pipework should ensure that it is sealed to the brickwork so that leakage is minimised. Non-return valves are recommended for the drainage systems to prevent backflow of diluted sewage. Again, internal white goods should be raised above flood levels and resilient materials for kitchen units are preferred even though these are more expensive. Overall, good workmanship is essential to ensure that all retrofit work is to the highest standard, particularly for a water-exclusion strategy.

\subsection{Benefits of the new guidance}

Developers and designers in the UK working in large construction companies and architectural practices will find this practical guidance invaluable in addressing the current absence of building regulations to adequately address flooding in new developments. It is essential that the construction industry offers innovative design solutions for flood resilient properties and this standard is the perfect tool for introducing such measures.
The guidance will also be useful to planners and building control officers in local authorities, large planning consultancy practices and loss adjusters, seeking to address the 'disconnect' between planning requirements and building regulations.

Further benefits of using this standard have been identified and include:

- Promoting the use of materials and construction elements that are more resilient to floodwaters.

- Minimising delays in reoccupying properties after flooding, which can have a profound impact on the health and livelihoods of those affected.

- The potential to reduce business losses as a result of reducing the impacts of flood events.

- The potential to reduce the risk of mould and other health risks related to flooding impacts which have been shown to be likely to increase as a result of climate change.

- The potential to save energy as a result of reducing the need for excessive drying and restoration of flooded properties.

Figure 5 [12] below shows typical damage curves comparing the expected benefits from using resistance and/or resilience measures.

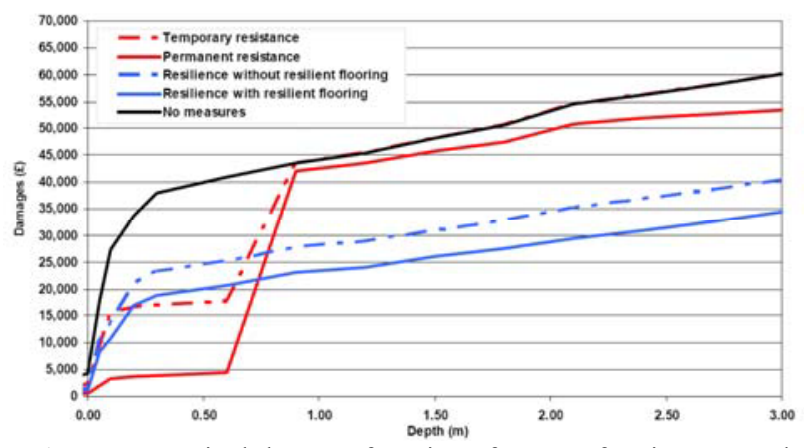

Figure 5. Typical damage functions for use of resistance and resilience measures

It can be seen that excluding floodwater with resistance provides major reductions in damage, at least up to the point at which it is no longer feasible to exclude water (i.e. for shallow floods). Then there is a small benefit throughout the depth range as a result of belongings having been removed upstairs or outside to avoid the water.

Whilst resilience measures are more costly, they can provide overall savings for more frequent (greater than $4 \%$ annual probability) or deeper (greater than $0.8 \mathrm{~m}$ ) flooding. This is because they provide an overall reduction in drying and refurbishment cost, irrespective of the flood depth. Although resilience has been viewed as an expensive option, studies are underway looking at options for low-cost resilience, and it is hoped that this will drive an increased uptake in the technology, which is currently dominated by resistance measures. 


\section{Other developments in resistance and resilience}

The inclusion of resistance and resilience measures in buildings is viewed as an important component of flood risk management that will assist in keeping pace with the impacts of climate change. For example, the UK Government has assumed that there needs to be an increased uptake of flood protection products to deal with local flood risk in the coming century. Here there is innovation in designs, including a move away from simple barriers over door and patio apertures to integral flood doors that rely on specialist seals and locks to form a watertight barrier to any floodwater. Interest in testing such devices to PAS1188 [4] remains high. The benefit of such flood doors is that they provide a more passive/automatic protection with no need for user action. This has been viewed as a weakness in that homeowners may not be present when flood barriers need to be flitted prior to a flood.

Alongside the production of the new BSI Standard, the Building Research Establishment (BRE) has also published guidance and information on resistant and resilient building approaches. In 2012, Digest 523 [13] set out an overall approach to building in flood-risk areas and the design of flood-resilient buildings, using a range of measures, including elements of resistance, resilience and avoidance. The approach was based on that developed in all parts of the UK in recent years. This was followed by a 'good building guide', which made use of the research undertaken in the SMARTeST project [5, 14]. This outlines steps that can be taken to protect buildings or communities against flooding by means of flood resilience technologies, that is, flood protection products which can provide resistance or resilience to flooding impacts. It is worth noting that this definition of resilience is wider than that adopted in the original DCLG guidance, where such protection products are classed as "resistance".

In terms of resilience measures for inclusion as part of the building fabric, recent research [15] has looked at the opportunities for low-cost options, as an early viewpoint was that such measures were expensive and therefore only cost-effective for more frequent flooding (see above). With the ever-present damage from major flooding, it is important that as many options are available to deal with this risk and that they are as costeffective as possible.

Finally, there is a steady progress in new innovative materials coming to market as a result of the greater awareness and experiences of flooding. This is associated with a better understanding of the performance of building materials from bespoke testing. For example, there has been an initiative in the USA since 2011 to develop a new testing standard to determine the flood damage resistance properties of materials [16]. The development of this standard has involved UK input. This Standard will establish contaminated water immersion, drying and cleaning procedures to be used when determining whether building materials are flood damage resistant.

\section{References}

1. Pitt, M. (2008). The Pitt Review: Lessons learned from the 2007 floods, Cabinet Office, June 2008.

2. Escarameia, M. (2012). Building flood resilience measures. Outline design guidance including roadmap for accelerated acceptance, FloodProBE, Report No. WP04-01-11-18, November 2012.

3. Escarameia, M., Walliman, N., Zevenbergen, C. and de Graaf, R. (2016). Methods of assessing flood resilience of critical buildings, Proc. Of the Institution of Civil Engineers, Water Management, Volume 169, Issue WM2, pp 57-64.

4. BSI (2014) PAS1 188:2014 Flood protection products - Specification. BSI Standards Limited, London July 2014.

5. SMARTeST Project https://www.bre.co.uk/page.jsp?id=3187, accessed $16 / 2 / 2016$.

6. ODPM (2003). Preparing for floods. Interim guidance for improving the flood resistance of domestic and small business properties. 2003 Reprint.

7. Flood Repairs Forum (2006). Repairing flooded buildings. Floods Repair Forum.

8. Escarameia, M. Karanxha, A. and Tagg, A. (2007). Quantifying the flood resilience properties of walls in typical UK dwellings, Building Services Engineering Research \& Technology, 28.3 (Aug 2007): p249

9. Department for Communities and Local Government (2007). Improving the Flood Performance of New Buildings. Flood Resilient Construction, May 2007, RIBA Publishing, London.

10. BSI (2008) Rethinking standards in construction Developing the next generation of construction standards. BSI, September 2008.

11. BSI (2015) BS 85500:2015 Flood resistant and resilient construction - Guide to improving the flood performance of buildings. BSI Standards Limited, London 2015

12. Defra (2008) Developing the evidence base for flood resistance and resilience. R\&D Summary Report FD2607/TR1. Defra, June 2008.

13. Garvin, S. (2012) Flood Resilient Building (DG 523), BRE Digest 523, BREPress, January 2012.

14. Garvin, S. and Hunter, K. (2014) Applying flood resilience technologies (GG 84), BRE Good Building Guide 84, BREPress, September 2014.

15. Defra low cost options http://www.floodandcoast.com/abstracts/jlamond.pdf

16. ASTM WK35237 (in progress) New Test Method for Standard Test Method for Water Immersion and Drying for Evaluation of Flood Damage Resistance. 